\title{
Coulisses
}

Revue de théâtre

6 | Printemps 1992

Varia

\section{Impressions du public}

Propos recueillis par Emmanuelle Ravot

\section{Emmanuelle Ravot}

\section{(2) OpenEdition}

\section{Journals}

Édition électronique

URL : http://journals.openedition.org/coulisses/1977

DOI : 10.4000/coulisses. 1977

ISSN : 2546-9460

Éditeur

Presses universitaires de Franche-Comté

\section{Édition imprimée}

Date de publication : 1 juin 1992

ISSN : 1150-594X

\section{Référence électronique}

Emmanuelle Ravot, «Impressions du public », Coulisses [En ligne], 6 | Printemps 1992, mis en ligne le

15 mars 2019, consulté le 23 octobre 2019. URL : http://journals.openedition.org/coulisses/1977 ;

DOI : 10.4000/coulisses. 1977

Ce document a été généré automatiquement le 23 octobre 2019

Coulisses 


\title{
Impressions du public
}

\author{
Propos recueillis par Emmanuelle Ravot
}

\section{Emmanuelle Ravot}

J'ai surtout été intéressée par la mise en scène, les éclairages. C'était superbe. Le personnage de Néron m'a un peu déconcertée. J'ai étudié la pièce il y a longtemps et je ne me souvenais pas avoir compris la personnalité de Néron comme ce que j'ai vu.

J'ai trouvé ça long, avec des tirades interminables...

Je connaissais la pièce et je savais ce que je venais voir. De plus, je connais Alain Françon car j'ai vu plusieurs de ses mises en scène. Il n'y a donc pas eu vraiment de surprise. J'ai retrouvé la qualité d'un metteur en scène que j'appréciais déjà. C'est un très beau spectacle, surtout visuellement - et une écoute de texte très forte.

C'est une belle photo sur papier glacé. Le metteur en scène donne des images mais pas un point de vue sur la pièce. Il manque une dimension... métaphysique.

$*$

J'ai eu du mal à entrer dans la pièce. J'ai trouvé les personnages statiques, avec les mains ouvertes, comme ça. Il y avait peu de gestes... 
La voix d'Agrippine m'a gênée. Elle était trop présente, trop manière tragique, rugissante, pas dans le style des autres personnages. C'est comme si elle jouait sa propre partition, différente des autres.

Oui, j'ai bien aimé... Mais j'aimerais bien qu'on me raconte la mise en scène, le pourquoi des différents espaces, le carré du milieu, le rideau rouge. J'aimerais qu'on me dise pourquoi il y a une tenue de page en noir; j'ai plein de choses à comprendre, il faudrait qu'on me décrypte la pièce.

Propos recueillis par Emmanuelle Ravot

Il semble bien que le public d'aujourd'hui consomme Racine d'une façon purement anthologique (...). Le texte lui-même est reçu comme un ensemble de matériaux où le plaisir fait son choix; des vers heureux, des tirades célèbres s'enlèvent sur un fond d'obscurité et d'ennui : c'est pour cette actrice, ces vers, ces tirades que l'on vient au théâtre ; le reste, on le supporte, au nom de la culture, au nom du passé, au nom d'une saveur poétique patiemment attendue parce qu'elle a été localisée par des siècles de mythe racinien. Le Racine public (je n'ose dire populaire), c'est ce mélange d'ennui et de fête, c'est-à-dire essentiellement un spectacle discontinu.

Roland Barthes, Sur Racine (p. 135)

Personnellement, quand je monte un classique, mon premier souci est de raconter quelque chose de perceptible à ceux qui ne connaissent pas la pièce. Mais c'est là aussi que les malentendus peuvent surgir : il y a dans la salle, et en particulier à la Comédie- Française, pêle-mêle des gens qui connaissent le texte par cœur, et des gens qui ne le connaissent pas du tout. Ma déontologie a toujours été de présenter le spectacle comme s'il s'agissait d'un texte inédit, c'est- à-dire pour ceux qui ne le connaissent pas. En ce qui concerne Racine, il faut bien avouer que le public non averti, non motivé par des raisons socio-culturelles, ne se rend pas facilement au spectacle. Aux souvenirs scolaires, en général très ennuyeux, viennent se superposer des expériences de spectateur souvent malheureuses, dans la mesure où, pour des raisons dues au langage trop ancien ou aux confusions d'objectifs, ou à l'absence de mise en scène, on n'a généralement rien compris à ce qui se passait sur le plateau : d'où un autre ennui profond, inexcusable, qui rend ensuite le spectateur méfiant, voire hostile, quand on lui propose une pièce de Racine (cela est valable aussi pour Corneille, bien sûr).

Jean-Pierre Miquel, Sur la tragédie (pp. 46-47) 